\title{
QUALITY OF LIFE IN PEDIATRIC CANCER SURVIVORS: A NEW CONTRIBUTION INCLUDING THE GOAL CONCEPT
}

\author{
Fabienne Lemétayer, Jean-Baptiste Lanfranchi, and Pascal Chastagner
}

\begin{abstract}
The present study focuses on quality of life in children survivors of cancer through the filter of self-regulation by goals. In this respect, the model of Dupuis and its operationalization by Missotten through the Child Quality of Life Systemic Inventory (QLSI-C(C) makes it possible to identify the regulation processes (state, goal, speed, rank), in order to distinguish between children survivors of cancer and their healthy peers, as well as identifying the impact of these processes on anxiety and depression symptoms. Fifty children survivors of cancer, aged 8 to 12 years, answered three questionnaires: the QLSI-C@ , the State-Trait Anxiety Inventory - Child (STAIC), and the Child Depression Inventory (CDI). Their responses were compared with those obtained from 50 healthy children of the same age. Partial Least Squares Discriminant Analysis (PLS-DA) was used to show that the process that best differentiated the two groups pointed to a regulation through goals and priorities. Results revealed too that these processes were particularly apparent in 8 of the 20 life domains examined. Moreover, of the four processes, state is the best predictor of depressive symptoms. Children survivors of cancer do not view their lives and plans in the same manner as their healthy peers. However, their different strategies of regulating goals and priorities do not result in more depressive symptoms than in their healthy peers. The question of whether more demanding goals and priorities are necessarily a source of well-being remains to be determined.
\end{abstract}

Keywords: Quality of life, goals, childhood, cancer survivors, PLS-DA

Acknowledgment: We sincerely thank the Ligue Nationale Contre le Cancer [French National League against Cancer] for its financial support.

Fabienne Lemétayer (the corresponding author) is a Professor in the APEMaC [EPSaM] Research Unit, Laboratory EA 4360, University of Lorraine, Île du Saulcy BP 30309 - 57006 METZ, Cedex 1, France. E-mail: fabienne.lemetayer@univ-lorraine.fr

Jean-Baptiste Lanfranchi is an Associate Professor in the APEMaC [EPSaM] Research Unit at the University of Lorraine, Metz, France. E-mail: lanfranchi@univ-metz.fr

Pascal Chastagner is a Professor in the Pediatric Oncology Department at the Nancy University Hospital - Hôpital de Brabois, Rue du Morvan, 54511 Vandoeuvre-lès-Nancy Cedex, France. E-mail: p.chastagner@chu-nancy.fr 
This study examines the quality of life of school-age children survivors of cancer with a new assessment tool, the Child Quality of Life Systemic Inventory (QLSI-C) (Missotten, Etienne, \& Dupuis, 2007). The major purpose of the study is to identify the processes and life domains in QLSI-C that are most likely to differentiate children survivors of cancer from healthy children, and to reveal the impact of these processes on anxiety and depression symptoms.

Although there are various forms and degrees of severity, cancers during the pediatric period invariably have repercussions on the personal lives of the children. In addition to diverse alterations of the state of health, they interfere with daily life activities such as attending school, and can impact the children's growth and development. Pediatric cancers also affect the family and social lives of those afflicted, due to the progressive nature of these cancers and because they can be particularly debilitating. Each year, about 1,500 children in France, that is, one out of 700 from birth to age 15, are afflicted with cancer, whether it be a hematological malignancy like leukemia, which accounts for about $30 \%$ of cancers in children, (Guyot-Goubin \& Clavel, 2009) or a solid tumour, like a brain or bone tumour, which account for a further 20\% (Désandes \& Lacour, 2009).

To this day, cancers during childhood remain of great concern. However, advances in medical treatments, surgery, and bone marrow transplants often enable pediatric oncologists to delay or divert a fatal outcome and, in many cases, even bring about remission (recovery) (Sommelet, 2009). Over the past three decades, the odds of recovery have been steadily rising, improving the prospects of up to $80 \%$ of childhood patients. However, pediatric cancer treatments are not mere routine. They remain painful and protracted (4 to 8 months), and usually involve uncomfortable or invasive procedures such as chemotherapy, radiotherapy, surgery, and cell grafts.

These treatments have manifold undesirable side effects: fatigue, hair loss, nausea and/or vomiting, fragility of the skin and digestive tract, susceptibility to infection, obesity (from cortisone use), and painful episodes regularly requiring the prescription of prophylactic drugs (pain medications, transfusions, antiemetics, antibiotics, etc.). Children and families may receive psychological counselling if there is non-adherence to treatment or difficulty in coping with the disease. Some side effects are reversible upon discontinuation of treatment, but in some cases long term quality of life may be seriously impaired. Chemotherapy can be responsible for physical after-effects including hearing, endocrine (e.g. stunting), and dental damage (Oberfield \& Sklar, 2002) while radiation therapy can result in cognitive impairments (Moore, 2005; Sommelet, 2009). Surgical mutilations such as amputations are rare, but when they occur, they significantly affect not only movement but also body image.

And yet, children survivors of cancer endeavour to return to the life they had before they became ill. Most of the time, the key step is going back to school, the place where they live their daily lives, have their friends, and develop. Returning to school is a symbol of their recovery and future, whereby afflicted children and especially those in remission regain their status as normal children like any other (Lemétayer, 2007). How does the post-cancer period impact the quality of life of these children once they return to school? What processes and life domains might account for differences in quality of life?

For around twenty years, research into measuring quality of life in pediatric cancer has continued to expand (Klassen, Strohm, Maurice-Stam, \& Grootenhuis, 2010). Some tools 
have been developed specifically to quantify the impact of cancer and cancer treatments on the daily lives of children in remission from cancer, based on answers provided by the children themselves; for example, the Minneapolis-Manchester Quality of Life Instrument (MMQL) (Bhatia et al., 2004), the Pediatric Quality of Life Inventory (PedsQL) (Varni, Burwinkle, Katz, Meeske, \& Dickinson, 2002), and the Pediatric Quality Of Life (PEDQOL) (Calaminus, Weinspach, Teske, \& Göbel, 2000). It is difficult to summarize concisely the results obtained in the literature following childhood cancer, due to the different criteria used in the studies: the age of participants (who may range from small children to young adults), the cancer type studied (from a specific type of cancer to a set of cancers), the impact of the family, et cetera. Thus, according to some accounts in the literature, quality of life after childhood cancer may be relatively satisfactory (Eiser, Vance, Glaser, \& Galvin, 2003; Löf, Winiarski, Giesecke, Ljungman, \& Forinder, 2009; Zebrack, Yi, Petersen, \& Ganz, 2008); in others it may be found to have deteriorated significantly, as in the study by Langeveld, Grootenhuis, Voute, and de Haan (2004) where 12\% of children in remission from cancer presented post-traumatic stress disorder.

Conversely, the common feature of these metrics is that they operate with a notion of quality of life that prioritizes the measurement of the individual's current situation. This approach appears to have been suggested by the definition of quality of life proposed by WHO (1994):

Quality of life is defined as an individual's perception of their position in life in the context of the culture and value system in which they live and in relation to their goals, expectations and standards and concerns. It is a broad ranging concept affected in a complex way by the person's physical health, psychological state, level of independence, social relationships, and their relationship to salient features of their environment (in Bowling, 2001).

Therefore, while each of the above instruments has relevance for assessing and measuring the quality of life of children survivors of cancer, they have a common shortcoming in that the goals of life are not addressed. Because an individual's perception of his or her ability to achieve valued goals is likely to have an impact on his or her current quality of life, however, research with a different orientation is also required. For this reason, in this study we prioritize the definition of quality of life proposed by Dupuis, which fully incorporates the concept of goals: "Quality of life, at a given time, is a state that corresponds to the level attained by a person in the pursuit of hierarchically organized goals" (Dupuis, Perrault, Lambany, Kennedy, \& David, 1989). The notion of goals, as understood here, refers to mental representations of a desired state (Carver \& Scheier, 1990). This notion also includes affects and behaviours:

"A cognitive image of an ideal stored in memory for comparison to an actual state; a representation of the future that influences the present; a desire (pleasure and satisfaction are expected from goal success); a source of motivation, an incentive to action” (Cochran \& Tesser, 1996, in Street, 2002).

For about thirty years, the study of the importance of personal goals in the life of the individual has figured prominently in the literature. For example, goals have been described as powerful predictors of satisfaction with life (Brunstein, Schultheiss, \& Grässmann, 1998; Emmons, 1996), self-esteem (Crocker \& Park, 2004), emotional wellbeing and physical health (Wrosch, Scheier, Miller, Schulz, \& Carver, 2003b), and as an important factor in quality of life (Wrosch, Scheier, Carver, \& Schulz, 2003a). 
In this study, the quality of life of children in remission from cancer will be assessed using a generic tool, and the results compared with the general population, focusing our analysis on the gap between the goals valued by the child and the assessment of the probability of reaching these goals. This perspective is located within the behavioral selfregulation model developed by Carver and Scheier (Carver, 2004; Carver \& Scheier, 1998; Scheier \& Carver, 2003) according to which "progress towards a goal reflects the action of a feedback loop” (Carver \& Scheier, 2009). This notion of the dynamic feedback process is itself largely inspired by cybernetics control theory, especially the "Test - Operate - Test Exit” (TOTE) model of Miller, Galanter, and Pribram (1960). In the Carver and Scheier model, negative feedback means that the behaviour of the individual has led to a reduction in the gap between a state and a goal (moving nearer to the set goal), while positive feedback signals an increase in the gap between a state and a goal (distance or avoidance of a goal) (Carver \& Scheier, 1998). However, the authors then add a second feedback loop to their model: evaluation of the speed of progress toward a goal, to measure the effects on the emergence of affects. Indeed, Carver and Scheier claim that speed of progress toward a goal can be compared to a reference value (desired speed) and, depending on the progress, different emotional consequences would result. A speed of progress below the reference value would favour negative affect, characterized by such feelings as anger, frustration, and sadness. Conversely, a progress speed higher than a reference value would create positive affect, with feelings such as enthusiasm and excitement (Carver \& Scheier, 2009).

We shall now discuss a final dimension borrowed from Carver and Scheier. This is management of priorities in terms of goals. This notion is considered by the authors to be an important indicator in assessing the difficulty that an individual has in disengaging from a valued goal that proves inaccessible. Difficulty in disengaging from a prioritized goal without an alternative is likely to cause anxiety and depression affects (Carver \& Scheier, 1981; Champion \& Power, 1995; McIntosh, 1996).

As with Carver and Scheier's behavioural self-regulation model, the quality-of-life measurement model proposed by Dupuis incorporates goals theory; relevant concepts include the discrepancy between a state and a goal, notions of speed of progress towards the goal, and management of priorities as indicators of negative feelings. Dupuis, Taillefer, Rivard, Roberge, and St-Jean (2001) aim to explain the reasons for the "ill-being" or the "well-being" of the individual who is genuinely engaged in achieving his or her life goals (cf. Figure 1). For these authors, whether one is in a condition of ill-being or well-being depends primarily on the comparison between the current situation and the desired situation, the goal. Thus, when there is no difference between the two situations ( $\mathrm{Gap}=0$ ), the person tends to be satisfied with their quality of life. Conversely, if there is a gap between the current situation and the goal (Gap>0), two situations are possible: either a negative feedback loop or a positive feedback loop. When the feedback is negative, it means that the child's behaviours ${ }^{1}$ cause the child to feel that he or she is close to the objectives (reducing the gap) thus increasing satisfaction. However, when the feedback is positive, the child's behaviours are counter-productive and the child feels that he or she is moving away from the objectives, widening the gap, and leading to a deterioration in quality of life that is likely to produce frustration or anger or symptoms of depression. This type of loop indicates a deteriorated quality of life.

\footnotetext{
${ }^{1}$ Here, behaviour means both self-regulated behaviour (e.g., coping) and other-regulated behaviour (e.g., parental expectations).
} 


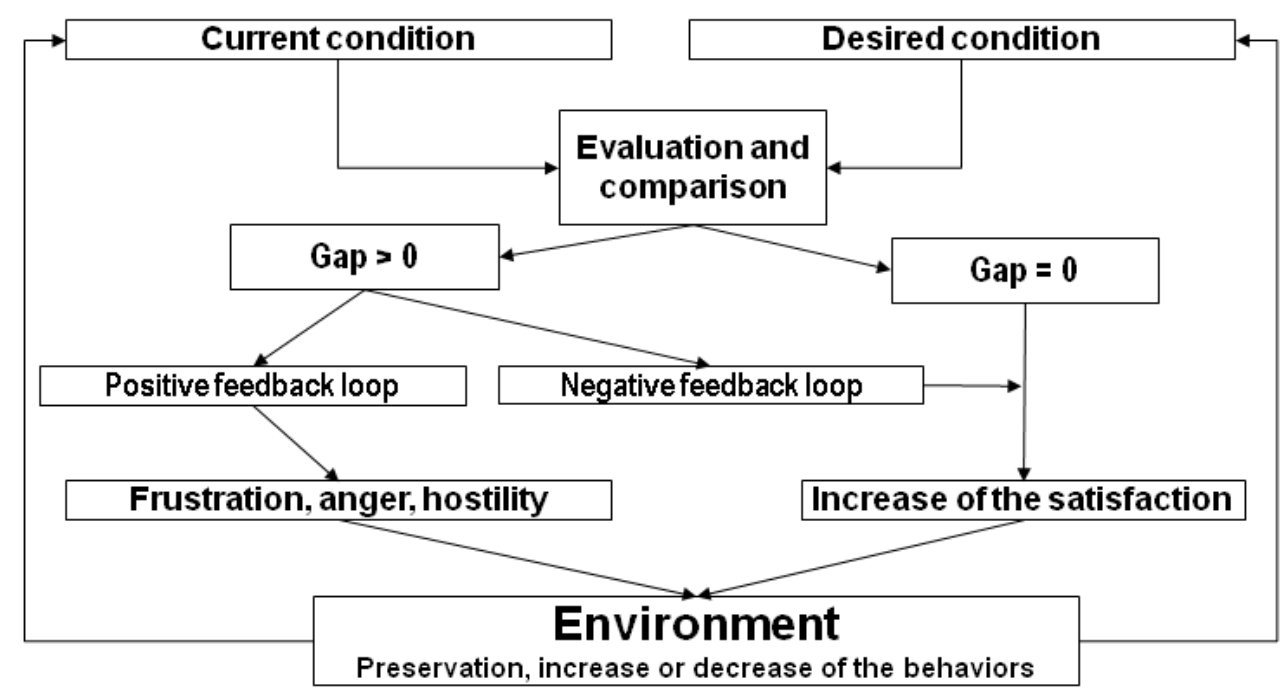

Figure 1. Theoretical model of QLSI-C. Dupuis, Taillefer, Rivard, Roberge and St-Jean (2001).

Aside from the influence of this perceived gap between the current state and the goal, the tensions or dissatisfactions endured also depend on the speed of achieving the goal and the importance of the goal for the individual. Elicker et al. (2010) have shown that, for young adults, a low perceived speed toward achieving an academic goal is a source of dissatisfaction. In addition, the importance of the goal is likely to exacerbate the negative effect of the low perceived speed. According to the literature, the importance attributed to one goal or a few goals, as the only springboards to happiness and well-being, is likely to cause depressive symptoms if the person cannot envisage alternatives. The individual who has fewer important goals considered as sources of wellbeing is at more risk of obsessing about failure to either achieve these goals or to disengage from them (Street, 2002; Street et al., 2004).

What is the current state of research in children survivors of cancer? To our knowledge, there has been no research on the simultaneous influence of the gap, the perceived speed, and the importance of goal in children survivors of cancer. Yet, should we assume, as suggested in the model of Dupuis et al. (2001), that a child will feel more tension if quickly reducing the gap between a state and a valued goal proves to be difficult? In this regard, the Child Quality of Life Systemic Inventory (QLSI-C) (Missotten et al., 2007) has proven to be a particularly interesting new instrument in that it allows the simultaneous measurement of multiple cognitive and emotional processes, as well as the assessment of contents linked to quality of life. QLSI-C is primarily intended for children from 8 to 12 years. It is a selfadministered, global, and subjective tool, and includes a generic module comprising 20 life domains (such as sleep, relations with mother, and school), with the possibility of adding a specific module for six domains related to the individual situation of the child. Finally, a notable feature of this model lies in the possibility of taking into account the individual goals of the child. QLSI-C has the advantage of operationalizing the intensity of these processes through four different scores in 20 life domains:

1. The state score provides information on the current condition of the child.

2. The goal score provides information on the child's expectations for each life domain.

3. The speed score indicates the speed in moving closer to or further away from the goal. 
4. The priority score depicts the degree of importance of the goals to be achieved.

For Dupuis et al. (2001), it is the combination of these measurements which, by means of the weighted gap (WG) score, provides information on the child's quality of life. The WG score corresponds to the gap between state and goal by life domain, as weighted by the speed of improvement or deterioration of each domain and the priority of the domain. Thus the WG score reflects a (state minus goal) deviation, moderated by speed and priority:

$$
\mathrm{WG}=(\text { state }- \text { goal }) \mathrm{x} \text { speed } \mathrm{x} \text { priority }
$$

However, when it comes to highlighting possible psychic shifts, the question must be addressed as to whether WG alone should be relied on for differentiating between children survivors of cancer and healthy children of the same age. With this perspective in mind, our study's first objective was to identify, among the six processes involved in QLSI-C, that is, state, goal, gap (state - goal), speed, priority, and WG ([state - goal] x speed x priority), those most suitable to discriminate between these two groups of children. Our second objective was to identify the life domains that would enable these two groups of children to be distinguished. Finally, among the factors discriminating the two groups, the aim was to identify the processes that are more predictive of anxiety and depressive symptoms.

\section{Method}

\section{Participants}

The study sample comprised 100 children aged 8 to 12 years divided into two groups:

- Group 1: 50 children survivors of cancer, median age $=9.5$ years; $\sigma=1.34$; min. 8 - max. $12 ; 50 \%$ boys and $50 \%$ girls. The children in this group were recruited in the pediatric oncology department of the Nancy University Hospital (Eastern France).

- Group 2: 50 healthy children, median age $=9.6$ years; $\sigma=0.50$; $\min .9-\max$. 10; $44 \%$ boys and $56 \%$ girls. The children in this group were without any serious health or family problems.

All children were enrolled in the mainstream school system in the Lorraine region. Most of the children (60\%) were from homes whose head of household was a blue-collar worker or pink-collar worker while $29 \%$ of the children had at least one parent who was a white-collar or knowledge worker. For $5 \%$ of the children, the head of household was a craftsperson, tradesperson, or farmer. Finally, $6 \%$ of responses did not indicate this criterion or could not be categorized. The two groups of children did not differ significantly in relation to the distribution of heads of household: blue/pink collar workers versus white/knowledge collar workers $\left(\mathrm{N}=89 ; \chi^{2}(1)=2.75\right.$, ns). The characteristics of the children survivors of cancer are listed in Table 1.

Due to the small size of our sample, coupled with the heterogeneity of data such as past cancer, the type of treatment received, the aggressiveness of the disease, and the stage of cancer at diagnosis, it was not possible to select and incorporate these data into the quality of life measurement. 
International Journal of Child, Youth and Family Studies (2015) 6(4.1): 709-729

Table 1

Characteristics of the children survivors of cancer

\begin{tabular}{|c|c|c|c|}
\hline & Median & Min. & Max. \\
\hline Age when diagnosed & 4.6 years & 4 months & 9 years \\
\hline Age at first interview & 9.5 years & 8 years & 12 years \\
\hline \multicolumn{4}{|l|}{ Treatment duration } \\
\hline Solid tumours $(N=36)$ & 6 months & 0 months & 1.2 years \\
\hline Heamatologic malignancies $(N=14)$ & 3 years & 3 months & 3.3 years \\
\hline Number of years since end of treatment & 4 years & 2 months & 10 years \\
\hline Relapses (N=3) (Solid tumours) & $\begin{array}{l}23 \text { months } \\
\text { (after end of treatment for 1st cancer) }\end{array}$ & 6 months & 2.1 years \\
\hline
\end{tabular}

All of the children in the study volunteered to participate with their parents' approval (signed informed consent document) and responded to different questionnaires. The study also underwent an ethics review and received official approval from the Comité de Protection des Personnes Est III [East III Person Protection Committee]. The research project was registered under the Reference numbers No. 2009-A01379-48 - No. CPP 10.02.05.

\section{Self-reported measurements}

Separate measurements of quality of life, anxiety, and depression were made.

The Child Quality of Life Systemic Inventory (QLSI-C) (Missotten et al., 2007) is used to measure quality of life in school-age children. The questionnaire consists of 20 life domains (see Table 2).

Table 2

Life domains of QLSI-C C

QLSI-C@ life domains

\begin{tabular}{llll}
\hline 1. Sleep & 6. Physical appearance & 11. Relations with siblings & 16. Sports activities \\
2. Food & 7. Bedroom & 12. Relations with friends & 17. Extracurricular activities \\
3. Pain & 8. Relations with grandparents & $\begin{array}{l}\text { 13. Opinion people around me have } \\
\text { about me }\end{array}$ & 18. Autonomy \\
4. Health & 9. Relations with mother & 14. School & 19. Obedience to authority \\
5. Clothes & 10. Relations with father & 15. School results & 20. Tolerance of frustration \\
\hline
\end{tabular}

QLSI-C is used to assess the gap between the children's current situation (step 1) and their personal goals (step 2) for the 20 life domains, each of which is rated in comparison to an ideal situation. The perceived requirement of the goals is then evaluated based on a dynamic of approaching or moving away from the goals (step 3). The deviation is then weighted based on the importance given to each life domain (step 4) (see Table 3). 
International Journal of Child, Youth and Family Studies (2015) 6(4.1): 709-729

Table 3

Processes (involved in, targeted by) QLSI-C C

Processes of the QLSI-C(C)

\begin{tabular}{|c|c|c|c|}
\hline State & $\begin{array}{l}\text { Information about the current situation of the } \\
\text { child. }\end{array}$ & Score $₫$ & $\begin{array}{l}\text { Current situation satisfactory } \\
\text { [QoL থ]. }\end{array}$ \\
\hline Goal & Information about the desired situation. & Score $₫$ & High expectations [QoL 刅. \\
\hline Speed (S) & $\begin{array}{l}\text { Information on the speed of approaching or } \\
\text { moving away from the goal. }\end{array}$ & Score $₫$ & $\begin{array}{l}\text { Strong feeling of improvement } \\
\text { [QoL 》]. }\end{array}$ \\
\hline Priority $(\mathrm{P})$ & $\begin{array}{l}\text { Information on the importance level among life } \\
\text { domains. }\end{array}$ & Score $₫$ & Weak importance of the domain. \\
\hline Gap (G) & $\begin{array}{l}\text { Distance to go to achieve a goal } \Rightarrow \text { (state - } \\
\text { goal) }\end{array}$ & Score $₫$ & $\begin{array}{l}\text { Short distance } \\
\text { [QoL থ]. }\end{array}$ \\
\hline Weighted Gap (WG) & $\begin{array}{l}\text { Mean distance between state and goal, } \\
\text { weighted by speed and priorities } \Rightarrow \text { (State - } \\
\text { Goal) } \times \text { S X P }\end{array}$ & Score $₫$ & $\begin{array}{l}\text { Short weighted distance } \\
\text { [QoL 刃्]. }\end{array}$ \\
\hline
\end{tabular}

Figure 2 is a summary of the various measurements performed.

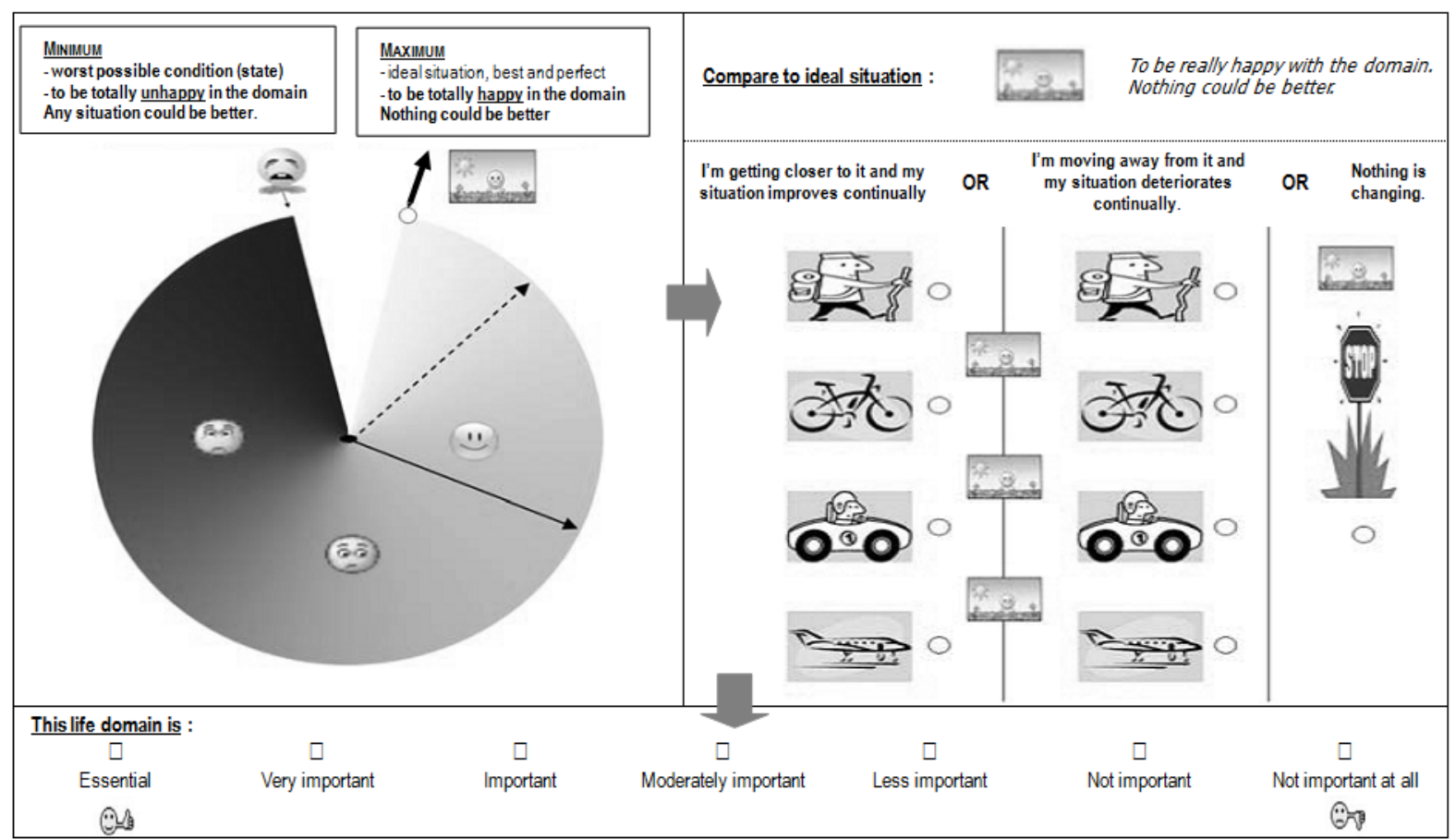

Figure 2. Different steps in QLSI-C. In the circle, solid line = state and dotted arrow = goal

The psychometric properties of the QLSI-C were satisfactory ( $\alpha=.86$ for State; 92 for Goal; .71 for Gap) (Etienne, Dupuis, Spitz, Lemétayer, \& Missotten, 2010).).

The State-Trait Anxiety Inventory for Children (STAIC-State) (Spielberger, Edwards, Lushene, Montuori, \& Platzek, 1973) was used in its French translation (Turgeon \& Chartrand, 2003). This scale assesses the transient anxious responses to specific situations 
(anxiety as Trait or Situation). It is designed for children aged 8 to 13 years. The children selfassess their condition by selecting the phrase that best describes how they have been feeling in the last few days. This "I feel..." scale includes 20 items, rated from 1 (neutral) to 3 (maximum intensity). The total score is obtained by summing the rating for each item, and may vary from 20 to 60 . The higher the score, the higher the anxiety. The psychometric properties of the French version of STAIC were satisfactory $(\alpha=0.88)$.

The Child Depression Inventory (CDI) (Kovacs, 1985, 1992) was employed in its French translation (Moor \& Mack, 1982 in Bouvard, 2008). This tool is used to test for and assess the presence and intensity of depressive symptoms. It includes 27 items. Each child is asked to choose one of three statements, corresponding to three levels of severity (0-neutral to 2-maximum intensity). According to Kovacs $(1985,1992)$, this scale can be used with children aged 8 to 17 years. The psychometric properties of the French version of CDI were satisfactory $(\alpha=0.70)$. The total score is obtained by summing the rating for each item, and can vary from 0 to 54 . The higher the score, the greater the depressive condition.

\section{Statistical methods}

A Partial Least Squares Discriminant Analysis (PLS-DA) was carried out to identify those among the 120 variables measured in a QLSI-C test (20 domains x 6 processes) that were the most likely to distinguish between the two groups of children. PLS-DA is a highly appropriate method when there is a large number of correlated to highly correlated predictors (VIF $>5$ ), and when the number of predictive variables $(\mathrm{X})$ is greater than the number of observations (Pérez-Enciso \& Tenenhaus, 2003). It is based on the same calculation principles as the univariate PLS regression but with a dichotomous variable Y (Wold, Sjöström, \& Eriksson, 2001). This analysis leads to a first grouping of $X$ predictors within mutually orthogonal $\mathrm{T}$ factor components while simultaneously maximising the covariance with the $\mathrm{Y}$ variable. Consequently, when the goals of the analysis are the discrimination and the reduction of the number of dimensions, it seems preferable to use the PLS regression rather than Principal Component Analysis (Barker \& Rayens, 2003).

The study of the contribution of each $\mathrm{X}$ variable to the $\mathrm{T}$ components and the differentiation of $\mathrm{y} 1$ and $\mathrm{y} 2$ is carried out by calculating a Variable Importance in Projection (VIP) score. This score is used to ultimately reduce the number of predictors in a second analysis. Herein, a VIP $>1$ rule was applied, which is commonly accepted in the literature for selecting the most adequate predictors (Chong \& Jun, 2005). Finally, the $\mathrm{Q}^{2}$ criterion, obtained by cross-validation, is a cut-off criterion for the number of $\mathrm{T}$ components necessary and sufficient to predict the $\mathrm{Y}$ variable (Tenenhaus, 1998). The $\mathrm{Q}^{2}$ criterion must be positive and increase by at least 0.05 to allow the addition of a new $\mathrm{T}$ component to the prediction equation of Y. Thus, in conjunction with $\mathrm{R}^{2}$ which expresses the model's goodness of fit or discriminant power, $\mathrm{Q}^{2}$ is a measurement of the predictive ability of the model.

Finally, once the $\mathrm{Y}$ variable is regressed on this new set of $\mathrm{T}$ components, this relation can either be commented directly or one can calculate the number of regression coefficients for each initial $\mathrm{X}$ variable that constitute these $\mathrm{T}$ components. We chose the latter option for this study.

The validation of the model was investigated in two ways. First, the correct and incorrect classification rates of the 100 participants were established using a confusion matrix. Second, the $\mathrm{R}^{2}$ and $\mathrm{Q}^{2}$ values obtained in our study were compared to those obtained by randomizing the inclusion of the 100 subjects into one of the two groups (drawing without replacement). Hence, $200 \mathrm{Y}_{\text {test }}$ variables were collected and PLS-DA analyses were repeated for each variable. Through this permutation test procedure, proposed by Pérez-Enciso and 
Tenenhaus (2003) in their own studies, we wanted to establish whether it was possible to obtain in random manner $\mathrm{R}^{2}$ test and $\mathrm{Q}^{2}$ test values superior to ours $\left(\mathrm{R}^{2}\right.$ obs and $\left.\mathrm{Q}^{2}{ }_{\text {obs }}\right)$ and, especially, with what frequency. By considering that the distributions of $\mathrm{R}^{2}$ and $\mathrm{Q}^{2}$ under the null hypothesis were approximated by the sets of $\mathrm{R}^{2}$ test and $\mathrm{Q}^{2}$ test values, a model would be declared valid if the frequency was below the usual unilateral threshold of $2.5 \%$.

\section{Results}

The data collected from the STAIC and CDI questionnaires will first be examined, before presenting the PLS-DA results. All analyses were performed using the XLStat (Addinsoft, 2011) software.

\section{Anxio-depressive scores}

As indicated in Table 4, the critical threshold for STAIC is a score above 30 (Spielberger et al., 1973). The results show that 62\% of children survivors of cancer described themselves as being significantly more subject to anxiety than their healthy counterparts, including $12 \%$ with an anxiety score above 40 .

Table 4

Anxiodepressive scores

Samples

\begin{tabular}{|c|c|c|c|c|c|c|}
\hline & & \multicolumn{2}{|c|}{$\begin{array}{l}\text { Cancer survivors } \\
\qquad(\mathrm{N}=50)\end{array}$} & \multicolumn{2}{|c|}{ Healthy $(\mathrm{N}=50)$} & \multirow[b]{2}{*}{ Test-T* } \\
\hline & & $M$ & $\sigma$ & M & $\sigma$ & \\
\hline STAIC & Mean score & 32.6 & 4.5 & 30.5 & 4.6 & \multirow[t]{2}{*}{$p=.011$} \\
\hline $\begin{array}{l}\text { Critical Threshold> } 30 \text { (Spielberger et al., } \\
\text { 1973) }\end{array}$ & Score $>30$ & $62 \%$ & & $44 \%$ & & \\
\hline CDI & Mean score & 11.2 & 6.2 & 10.5 & 5.9 & \multirow[t]{2}{*}{ NS } \\
\hline $\begin{array}{l}\text { Critical Threshold } \geq 19 \text { (Kovacs, 1985, } \\
\text { 1992) }\end{array}$ & Score $\geq 19$ & $18 \%$ & & $10 \%$ & & \\
\hline
\end{tabular}

${ }^{*}$ T-Test (unilateral threshold; $\left.p<.025\right)$

For CDI, the critical threshold is a score above 19 (Kovacs, 1985, 1992). Results show that children survivors of cancer were more likely to present a depressive condition (18\%), although the difference between the two groups of children did not reach significance.

\section{PLS-DA results}

A primary PLS-DA analysis conducted on the 120 variables led to the elimination of 71 variables with a VIP $<1$. In the second analysis, only one significant $\mathrm{T}_{1}$ component was extracted by cross-validation $\left(\mathrm{Q}^{2}{ }_{\text {obs }}=0.282\right)$ taking into account the $34.5 \%\left(\mathrm{R}^{2}\right.$ obs $)$ variance in the dichotomous child group criterion (children survivors of cancer vs. healthy children). Given that the second component $\mathrm{T}_{2}$ had a negative $\mathrm{Q}^{2}$ obs $(-0.171)$, no other component was able to improve the capacity to predict which of the two groups a child belonged to.

The purpose of Table 5 is to examine the ability of the processes and domains to predict whether the subjects belonged to one of the two groups. Of the 49 variables retained, 7 
were related to the child's state, 17 to goal, 2 to speed, 9 to priorities, 9 to gap, and 5 to weighted gap. The processes were expressed in 17 of the 20 domains examined, whereas the analysis failed to retain the Mother, Siblings, and Friends domains.

In Table 5, the first two columns respectively refer to the standardized regression coefficients and the standard error obtained by the Jackknife resampling method. The correlation between each predictor retained and the dichotomous variable (coded 1 for children survivors of cancer and 0 for healthy children) is provided in the third column by calculating the Point-Biserial Correlation Coefficient (PBCC). The fourth column indicates the relative contribution (RCT) of each variable in differentiating the two groups as a percentage of $\mathrm{R}^{2}$ obs by applying the following formula:

$$
\mathrm{RCT}=\left(\beta \times \mathrm{PBCC} / \mathrm{R}_{\text {obs }}^{2}\right) \times 100
$$

Thus, for variable B01 (goal_sleep), RCT $=(0.042 \times 0.372 / 0.345) \times 100=4.5 \%$. This product measurement is one of the putative estimates of the importance of each predictor in this regression equation (Nathans, Oswald, \& Nimon, 2012). The sum of RCTs being 100\%, it also is used to calculate an RCT for each process in the last column by aggregating the RCTs of the predictors belonging to the same process.

Table 5

PLS-DA Results

\begin{tabular}{|c|c|c|c|c|c|}
\hline Variables & $\beta$ & SE $\beta$ & PBCC & RCT & RCT/Processes \\
\hline G01 - goal_sleep & $0.042^{\star \star \star}$ & 0.006 & $0.372^{\star \star \star}$ & 4.5 & \multirow{17}{*}{$56.9 \%$} \\
\hline G02 - goal_food & $0.042^{\star \star *}$ & 0.010 & $0.373^{* \star *}$ & 4.5 & \\
\hline G03 - goal_pain & $0.025^{\star \star *}$ & 0.007 & $0.226^{\star \star}$ & 1.6 & \\
\hline G04 - goal_health & $0.036^{\star *}$ & 0.016 & $0.326^{* \star *}$ & 3.4 & \\
\hline G05 - goal_clothes & $0.048^{* * *}$ & 0.008 & $0.427 * \star \star$ & 5.9 & \\
\hline G06 - goal_appearance & $0.050^{* * *}$ & 0.008 & $0.448 * \star *$ & 6.5 & \\
\hline G07 - goal_bedroom & 0.023 & 0.022 & $0.206^{\star \star \star}$ & 1.4 & \\
\hline G08 - goal_grandparents & $0.039 * \star *$ & 0.012 & $0.354^{\star \star \star}$ & 4.1 & \\
\hline G09 - goal_father & $0.028 * \star *$ & 0.010 & $0.252^{* \star *}$ & 2.1 & \\
\hline G10 - goal_people/about me & $0.036^{\star \star *}$ & 0.012 & $0.321^{\star \star \star}$ & 3.3 & \\
\hline G11 - goal_school & 0.025 & 0.017 & $0.220 * \star \star$ & 1.6 & \\
\hline G12 - goal_school results & $0.024^{\star \star}$ & 0.010 & $0.214^{\star \star \star}$ & 1.5 & \\
\hline G13 - goal_sports & $0.022^{\star *}$ & 0.010 & $0.193^{\star *}$ & 1.2 & \\
\hline G14 - goal_extra activities & $0.028^{*}$ & 0.017 & $0.248 * \star \star$ & 2.0 & \\
\hline G15 - goal_autonomy & $0.036^{*}$ & 0.007 & $0.323^{\star \star \star}$ & 3.4 & \\
\hline G16 - goal_obedience & $0.037^{\star *}$ & 0.014 & $0.333^{\star * *}$ & 3.6 & \\
\hline G17 - goal_frustration & $0.049 * * *$ & 0.005 & $0.444^{* * *}$ & 6.4 & \\
\hline P01 - priority_sleep & $-0.029 * * *$ & 0.011 & $-0.262^{\star \star \star}$ & 2.2 & \multirow{4}{*}{$15.0 \%$} \\
\hline P02 - priority_food & $-0.030^{\star \star \star}$ & 0.012 & $-0.271^{\star \star \star}$ & 2.4 & \\
\hline P03 - priority_health & $-0.029^{* * *}$ & 0.010 & $-0.257^{\star \star \star}$ & 2.1 & \\
\hline P04 - priority_clothes & -0.021 & 0.019 & $-0.186^{\star \star}$ & 1.1 & \\
\hline
\end{tabular}

${ }^{*} p<.10 .{ }^{* *} p<.05 .{ }^{* * \star} p<.01 . G a=$ Gap (State minus Goal) 
International Journal of Child, Youth and Family Studies (2015) 6(4.1): 709-729

Table 5

PLS-DA (continued)

\begin{tabular}{|c|c|c|c|c|c|}
\hline Variables & $\beta$ & SE $\beta$ & PBCC & RCT & RCT/Processes \\
\hline P05 - priority_grandparents & $-0.031^{\star \star \star}$ & 0.007 & $-0.281^{\star \star \star}$ & 2.6 & \\
\hline P06 - priority _father & -0.021 ** & 0.011 & $-0.187^{\star \star}$ & 1.1 & \\
\hline P07 - priority_school & $-0.027^{\star \star}$ & 0.012 & $-0.244^{\star \star \star}$ & 1.9 & \\
\hline P08 - priority_school results & $-0.019 * *$ & 0.009 & -0.166 & 0.9 & \\
\hline P09 - priority_frustration & -0.016 & 0.010 & -0.145 & 0.7 & \\
\hline Ga01 - gap_food & -0.023 & 0.017 & $-0.209^{\star \star \star}$ & 1.4 & \multirow{9}{*}{$12.9 \%$} \\
\hline Ga02 - gap_pain & $-0.022^{\star \star}$ & 0.010 & $-0.201^{\star \star}$ & 1.3 & \\
\hline Ga03 - gap_clothes & $-0.028^{*}$ & 0.017 & -0.250 *** & 2.0 & \\
\hline Ga04 - gap_bedroom & -0.030 *** & 0.010 & $-0.270^{\star \star \star}$ & 2.4 & \\
\hline Ga05 - gap_siblings & $-0.022^{\star *}$ & 0.010 & $-0.193^{\star \star}$ & 1.2 & \\
\hline Ga06 - gap_sports & -0.021 & 0.018 & $-0.189 \star \star$ & 1.2 & \\
\hline Ga07 - gap_extra activities & $-0.021^{\star}$ & 0.011 & $-0.189 \star \star$ & 1.2 & \\
\hline Ga08 - gap_autonomy & -0.021 & 0.019 & $-0.187^{\star *}$ & 1.1 & \\
\hline Ga09 - gap_frustration & $-0.021^{\star \star}$ & 0.010 & $-0.209 \star \star \star$ & 1.2 & \\
\hline St01 - state_appearance & 0.021 & 0.018 & $0.193^{\star \star}$ & 1.2 & \multirow{7}{*}{$6.9 \%$} \\
\hline St02 - state_father & $0.024^{*}$ & 0.014 & $0.217^{\star \star}$ & 1.5 & \\
\hline St03 - state_people/about me & $0.015^{\star \star}$ & 0.006 & 0.133 & 0.6 & \\
\hline St04 - state_school & $0.021 * \star \star$ & 0.007 & $0.185^{\star}$ & 1.1 & \\
\hline St05 - state_school results & $0.020^{\star * \star}$ & 0.006 & $0.179 *$ & 1.0 & \\
\hline St06 - state_obedience & $0.021^{\star \star}$ & 0.010 & $0.192^{*}$ & 1.2 & \\
\hline St07 - state_frustration & 0.010 & 0.010 & 0.088 & 0.2 & \\
\hline Wg01 - WG_pain & $-0.022^{\star \star}$ & 0.010 & $-0.195^{\star}$ & 1.2 & \multirow{5}{*}{$5.7 \%$} \\
\hline Wg02 - WG_clothes & $-0.024^{*}$ & 0.014 & $-0.219 \star *$ & 1.5 & \\
\hline Wg03 - WG_bedroom & $-0.018^{\star *}$ & 0.009 & -0.165 & 0.9 & \\
\hline Wg04 - WG_siblings & $-0.018^{\star \star \star}$ & 0.006 & -0.161 & 0.8 & \\
\hline Wg05 - WG_autonomy & $-0.022^{\star \star}$ & 0.011 & $-0.196^{*}$ & 1.2 & \\
\hline S01 - speed_grandparents & $0.015^{\star *}$ & 0.008 & 0.138 & 0.6 & \multirow{2}{*}{$2.6 \%$} \\
\hline S02 - speed_frustration & $0.027^{*}$ & 0.014 & $0.246^{\star \star}$ & 2.0 & \\
\hline
\end{tabular}

${ }^{\star} p<.10 .{ }^{* \star} p<.05 .{ }^{* \star \star} p<.01 . W G=$ Weighted Gap (State minus Goal $x$ S $\times R$ )

Based on the 49 variables retained, the processes that contributed the most to $\mathrm{R}_{\text {obs }}^{2}=$ $34.5 \%$ mostly referred to the goal, and to a lesser extent to priority and gap (state - goal). These results also show that children survivors of cancer had less demanding goals than healthy children (56.9\% of $\mathrm{R}^{2}$ obs), that they attached less importance to the life domains retained by their peers ( $15.0 \%$ of $\left.\mathrm{R}^{2}{ }_{\mathrm{obs}}\right)$, and finally, that they perceived they had less distance to go to reach their goals than the healthy children group $\left(12.9 \%\right.$ of $\left.\mathrm{R}^{2}{ }_{\mathrm{obs}}\right)$. The other variable types, namely state, weighted gap, and speed, yielded a far weaker contribution: between $6.9 \%$ and $2.6 \%$ of $\mathrm{R}^{2}$ obs. 
Upon aggregation of the 49 variables as a function of the 17 available domains and after calculation of the RCT for each of these domains, eight of the variables appeared to moderately contribute to the $\mathrm{R}^{2}$ obs (see Table 6). Clothes, Tolerance of frustration, Food, Physical appearance, Relations with grandparents, Sleep, Autonomy, and Health were the domains in which children survivors of cancer differed the most from healthy children. An $\mathrm{R}^{2}{ }_{\text {obs }}$ contribution score below 5\% was observed for the following domains: Relations with father (4.7\%), Bedroom (4.6\%), School (4.6\%), Pain (4.2\%), Obedience (4.2\%), Way friends talk about me (3.9\%), School results (3.4\%), Extracurricular activities (3.1\%), Sports (2.4\%), and Relations with siblings (2\%).

Table 6

Domains contributing most to $R^{2}$

\begin{tabular}{lc}
\hline Domains & Contribution in relation to $\mathrm{R}^{2}$ \\
\hline Clothes & $10.6 \%$ \\
Tolerance of frustration & $10.4 \%$ \\
Food & $8.3 \%$ \\
Appearance & $7.7 \%$ \\
Grandparents & $7.2 \%$ \\
Sleep & $6.7 \%$ \\
Autonomy & $5.7 \%$ \\
Health & $5.6 \%$ \\
\hline Others (10 domains) & $<5 \%$ \\
\hline
\end{tabular}

\section{Quality assessment of the PLS-DA}

Table 7, by means of a confusion matrix, provides the results of the classification procedure obtained by applying the discriminant function on the entire population sample, upon which $81 \%$ of the children were correctly classified. This percentage was much higher than the percentage obtained "by chance alone", that is, $50 \%$ with two groups having an equal number of subjects.

Table 7

Confusion Matrix

\begin{tabular}{lcc|c|l}
\hline \multicolumn{1}{c}{ Pred. } & Cancer survivors & Healthy & Total & $\%$ correct \\
Obs. & & & & \\
\hline Cancer survivors & 37 & 13 & 50 & $74 \%$ \\
Healthy & 6 & 44 & 50 & $88 \%$ \\
\hline Total & 43 & 57 & 100 & $81 \%$ \\
\hline
\end{tabular}

However, it should be noted that the discriminant function was far more efficient in healthy children (88\% correctly ranked children) than in children survivors of cancer (74\% correctly ranked). The healthy children group was thus more homogeneous than the group of patient survivors of cancer. 
Finally, analysis of the results obtained by randomizing $200 \mathrm{Y}_{\text {test }}$ variables was used to attest that obtaining the $\mathrm{R}^{2}$ obs and $\mathrm{Q}^{2}$ obs levels by chance was difficult to achieve in the present study. None of the $200 \mathrm{Q}^{2}$ test were above the $\mathrm{Q}^{2}$ obs (with a frequency lower than $0.5 \%$ ) and only one $\mathrm{R}_{\text {test }}$ in 200 was higher than the $\mathrm{R}^{2}$ obs (frequency lower than $1 \%$ ). Table 8 provides a sample of the descriptive statistical data regarding these indicators.

Table 8

Descriptive Statistics of $Q^{2}{ }_{\text {test }}$ and $R^{2}$ test

\begin{tabular}{lrr}
\hline & $Q^{2}$ test & $R^{2}$ test \\
\hline No. of draws & 200 & 200 \\
Minimum & -0.399 & 0.070 \\
Maximum & 0.120 & 0.353 \\
1st Quartile & -0.181 & 0.121 \\
Median & -0.097 & 0.160 \\
3rd Quartile & -0.044 & 0.196 \\
Mean & -0.116 & 0.164 \\
Std. deviation (n) & 0.100 & 0.052 \\
\hline
\end{tabular}

\section{Influence of the 49 variables used in the PLS-DA on depression (CDI)}

To see how the 49 variables selected in the PLS-DA were able to explain the anxiety and depression suffered by the children, two PLS analyses were carried out. First, we regressed the STAIC score on these 49 QLSI-C variables and then reproduced the same analysis with the CDI score. It turned out that only the CDI score could be predicted by these variables due to a $\mathrm{Q}^{2}$ obs greater than $0\left(\mathrm{Q}^{2}{ }_{\text {obs }}=0.394\right.$ with two $\mathrm{T}$ components selected and 21 variables at the end). Indeed anxiety, measured through the STAIC, could not be effectively predicted from this same batch of variables $\left(\mathrm{Q}^{2}{ }_{\mathrm{obs}}=-0.006\right)$. Accordingly, we then only specified the results for the depressive symptoms. Hence, following a first analysis with all 49 starting predictor variables, a second analysis was performed with the 21variables having a VIP $>1$. Two extracted T components then enabled $55.5 \%\left(\mathrm{R}^{2}{ }_{\mathrm{obs}}\right)$ of the variance in responses to the CDI to be taken into account. Table 9 shows, in the same order as in Table 5 , the results of this PLS regression. Only the PBCC heading was replaced by PCC to denote Pearson's correlation coefficient among the variables selected from the QLSI-C and the CDI score.

These results suggest that the factors differentiating the groups of children are only partly the source of their depressive symptoms. Indeed, it is no longer the goals that are first here but the states experienced by the children in six life areas (56.4\% of $\left.\mathrm{R}^{2}{ }_{\text {obs }}\right)$ : the more the child is dissatisfied with his or her current relationship with authority (St06), with school or with school grades (St04 \& St05), in his or her reaction to the way others talk about him or her (St03), and his or her management of frustration (ST07), the more he or she confirms depressive symptoms associated with states. This pattern persists, but less decisively, when considering differences relating to food ( $\mathrm{Ga} 01)$, frustration ( $\mathrm{Ga} 09$ ), clothes (Ga03), and sport (Ga06) with a contribution of $18.4 \%$ to $\mathrm{R}^{2}{ }_{\text {obs }}$ : the more the child perceives a significant gap in these fields, the more this tends to contribute to depression. Finally, only three out of eight goal variables have a significant link with the CDI (6.4\% of $\left.\mathrm{R}^{2}{ }_{\mathrm{obs}}\right)$ : the more the child has 
demanding goals ${ }^{2}$ regarding food (G02), health (G04), and appearance (G06), the more these can contribute to symptoms of depression. By contrast, undemanding goals related to school (G11 \& G12), sport (G13), autonomy (G15), and even authority (G16) have the joint effect of accentuating depression complaints $\left(11.0 \%\right.$ of $\mathrm{R}^{2}{ }_{\mathrm{obs}}$ ) but are not significantly related to depression. Other variables such as the weighted deviation relative to the child's room (Wg03), priorities in relation to grandparents (P05), and school results (P08) have an insignificant minor influence (7.8\% of $\left.\mathrm{R}^{2}{ }_{\mathrm{obs}}\right)$.

Table 9

PLS regression of depression (CDI) on QLSI-C variables

\begin{tabular}{|c|c|c|c|c|c|}
\hline Variables & $\beta$ & SE $\beta$ & PCC & RCT & RCT/Processes \\
\hline G02 - Goal_Food & $-0.148^{\star \star \star}$ & 0.036 & -0.158 & 4.2 & \multirow{8}{*}{17.4} \\
\hline G04 - Goal_Health & $-0.092^{\star \star}$ & 0.043 & -0.076 & 1.3 & \\
\hline G06 - Goal_Appearance & $-0.095^{\star \star \star}$ & 0.034 & -0.095 & 0.9 & \\
\hline G11 - Goal_School & 0.029 & 0.066 & $0.239 * \star$ & 1.3 & \\
\hline G12 - Goal_School results & 0.064 & 0.050 & $0.284^{\star \star *}$ & 3.3 & \\
\hline G13 - Goal_Sports & 0.066 & 0.042 & $0.302^{\star \star *}$ & 3.6 & \\
\hline G15 - Goal_Autonomy & 0.052 & 0.080 & $0.259 * \star *$ & 2.4 & \\
\hline G16 - Goal_Obedience & 0.012 & 0.042 & $0.197^{*}$ & 0.4 & \\
\hline P05 - Priority_Gd-parents & -0.052 & 0.058 & -0.220 ** & 2.1 & \multirow[b]{2}{*}{2.5} \\
\hline P08 - Priority_School results & -0.013 & 0.058 & $-0.185^{\star}$ & 0.4 & \\
\hline Ga01 - Gap_Food & $0.146^{\star \star \star}$ & 0.051 & $0.304^{\star \star \star}$ & 8.0 & \multirow{4}{*}{18.4} \\
\hline Ga03-Gap_Clothes & $0.064^{\star *}$ & 0.029 & $0.225^{\star \star}$ & 2.6 & \\
\hline Ga06-Gap_Sports & $0.071^{*}$ & 0.037 & $0.221^{\star *}$ & 2.8 & \\
\hline Ga09 - Gap_Frustration & $0.125^{\star \star \star *}$ & 0.036 & $0.221^{\star *}$ & 5.0 & \\
\hline St01 - State_Appearance & 0.101 & 0.069 & $0.338^{\star \star \star}$ & 6.1 & \multirow{6}{*}{56.4} \\
\hline St03 - State_People/about me & $0.141^{\star * \star}$ & 0.044 & $0.395^{\star \star \star}$ & 10.0 & \\
\hline St04 - State_School & $0.108^{\star \star \star}$ & 0.022 & $0.394^{\star \star *}$ & 7.7 & \\
\hline St05 - State_School results & $0.144^{\star \star *}$ & 0.017 & $0.438 * \star *$ & 11.4 & \\
\hline St06 - State_Obedience & $0.176^{\star \star \star}$ & 0.063 & $0.502^{\star \star \star}$ & 15.9 & \\
\hline St07 - State_Frustration & $0.108^{\star \star *}$ & 0.032 & $0.270 * \star *$ & 5.3 & \\
\hline Wg03 - WG_Bedroom & 0.124 & 0.091 & $0.240^{\star \star}$ & 5.3 & 5.3 \\
\hline
\end{tabular}

${ }^{*} p<.10 .{ }^{* \star} p<.05 .{ }^{\star \star \star} p<.01$. Reminder: WG = Weighted Gap (State-Goal $\times S \times R$ )

\footnotetext{
${ }^{2}$ Remember that the more demanding the goal, the lower the score of this variable (see Table 3).
} 


\section{Discussion}

The aim of the present study was to identify the processes and life domains of the Child Quality of Life Systemic Inventory (QLSI-C) that best enabled the differentiation of children survivors of cancer from control healthy children, in order to assess the extent to which these differentiating factors are also involved in anxiety and depression symptoms in these groups of children.

The results obtained yielded a number of key elements. First, QLSI-C was well able to differentiate the two groups of children as highlighted by the fact that children survivors of cancer and their healthy counterparts differed in 17 of the 20 life domains.

Second, the capacity for QLSI-C to differentiate between the two groups does not result, as first assumed, from the interaction of processes being assessed through weighted gap calculation [WG = (state - goal) $\mathrm{x}$ speed x priority]. According to Dupuis et al. (2001), weighted gap is predominant in QLSI-C, since this is basically the interactive process for measuring quality of life. However, in the present instance, this interactive process was not the best differentiation indicator between the two study groups.

Third, our study highlights the fact that the processes that best discriminate between the two groups of children are first, the demands that the children place on the satisfactory achievement of their goals, and, less importantly, the priority given to these goals. In a nutshell, goals are involved in behaviour control in that they produce intentions to achieve the goals through personal effort (Brandtstädter, 2009). However, when goals are set too high, or are perceived as unattainable, it remains possible to disengage oneself from them and to commit oneself instead to other goals that are more achievable or more important (Carver \& Scheier, 1998; Wrosch et al., 2003a; Wrosch, Miller, Scheier \& Brun de Pontet, 2007). At this stage, the role of goals can be two-fold. On the one hand, having goals appears to be a strong predictor of satisfaction in life (Brunstein et al., 1998; Emmons, 1996). Nevertheless, unachievable goals can become a source of dissatisfaction (Brandtstädter, 2009; Brandtstädter \& Rothermund, 2002).

In this study, children survivors of cancer differed from their age-matched peers by their less demanding goals (for an identical State). This means that, like their peers, these children are committed to pursuing goals, but that their goals are more within their reach and easier to achieve than those expressed by healthy children. In this way, children cancer survivors can seem even more flexible and resilient than healthy children. Because there are fewer obstacles to achieving their goals, children survivors of cancer have less need to manage frustration than healthy children. The question remains, therefore, how can this tempering of goals be explained in children who are former cancer patients? To the best of our knowledge, there are no studies in the literature that have investigated the tempering of life goals during the pediatric period, let alone in children survivors of cancer. Based on the data collected from studies on adults (Wrosch et al., 2003a; Wrosch et al., 2003b), we could assume that children survivors of cancer would perceive undemanding life goals as more secure and predictable, more conducive to maintaining emotional balance. Additionally, these more realistic goals would also allow an easier mobilization of control, endurance, and planning processes, which may lead to greater overall achievement than if more demanding goals were adopted.

Finally, this study shows that QLSI-C can also be used to differentiate the two groups of children based on life domains. Of the twenty life domains assessed in the QLSI-C, eight domains differentiated the two groups, especially for the processes of goals, priorities, and 
gaps:. Clothes, Tolerance of frustration, Food, Physical appearance, Relations with grandparents, Sleep, Autonomy, and Health. As shown herein, practitioners supporting childhood cancer survivors should increase their awareness of these eight life domains.

QLSI-C data show that survivors of childhood cancer do not perceive their lives and life plans in the same manner as their healthy peers. However, is this better or worse? While our results do not explain the level of anxiety-state of the children, it seems, by contrast, that depressive symptoms are predominantly fed by the factor-state in which they see themselves in relation to their adjustment to the demands of the school environment in terms of work, discipline, and relationships with others. But this factor-state only determines a slight difference between the two groups of children (RCT $<7 \%$ ). Accordingly, the experience of a serious disease does not entail a perception that one is worse through a more degraded state than healthy peers. Here, regulation by goals, priorities, and gaps has less power to explain depression, probably because the state measurement is a proxy variable of the measurement of depression. What the results do show us, still in the study of differentiation between healthy children and children survivors of cancer, is that less demanding goals, among children survivors of cancer, are particularly effective in protecting against depression in the areas of food, appearance, and health but not necessarily in other areas. But everything also depends on the path taken between the current state and a demanding goal: too big a gap remains a source of suffering (Higgins, Bond, Klein, \& Strauman, 1986).

These results indicate that children who have had a serious illness should be regarded as regulating their goals differently from ordinary children, without these strategies necessarily making them more vulnerable to depression. However, the influence of these factors on the development of well-being, especially the process of goals and goal priorities, still needs to be researched, particularly insofar as they relate to positive psychology measurements (self-esteem, vitality, and general life satisfaction) to see if the various strategies of children who have had to live with a chronic disease are really triggers for the development of well-being. 
International Journal of Child, Youth and Family Studies (2015) 6(4.1): 709-729

\section{References}

Addinsoft. (2011). XLStat (Version 2011.2.05). Retrieved from http://www.xlstat.com/fr/addinsoft/societe.html

Barker, M., \& Rayens, W. (2003). Partial least squares for discrimination. Journal of Chemometrics, 17, 166-173. http://dx.doi.org/10.1002/cem.785

Bhatia, S., Jenney, M. E., Wu, E., Bogue, M. K., Rockwood, T. H., Feusner, ... Kane, R. L. (2004). The Minneapolis-Manchester Quality of Life instrument: Reliability and validity of the youth form. The Journal of Pediatrics, 145, 39-41. http://dx.doi.org/10.1016/j.jpeds.2004.02.034

Bouvard, M. (2008). Echelles et questionnaires d'évaluation chez l'enfant et l'adolescent [Scales and evaluation questionnaires for child and adolescent]. Issy-les-Moulineaux, France: Elsevier/Masson.

Bowling, A. (2001). Measuring Disease (2nd ed.). Buckingham, U.K.: Open University Press.

Brandtstädter, J. (2009). Goal pursuit and goal adjustment: Self-regulation and intentional self-development in changing developmental contexts. Advances in Life Course Research, 14, 52-62. http://dx.doi.org/10.1016/j.alcr.2009.03.002

Brandstädter, J., \& Rothermund, K. (2002). The life-course dynamics of goal pursuit and goal adjustement: A two-process framework. Developmental Review, 22, 117-150. http://dx.doi.org/10.1006/drev.2001.0539

Brunstein, J. C., Schultheiss, O. C., \& Grässmann, R. (1998). Personal goals and emotional well-being: The moderating role of motive dispositions. Journal of Personality and Social Psychology, 75, 494-508. http://dx.doi.org/10.1037//0022-3514.75.2.494

Calaminus, G., Weinspach, S., Teske, C., \& Göbel, U. (2000). Quality of life in children and adolescents with cancer. Klinische Pädiatrie, 212, 211-215. http://dx.doi.org/10.1055/s-2000-9679

Carver, C. S. (2004). Self-regulation of action and affect. In R. F. Baumeister \& K. D. Vohs (Eds.), Handbook of self-regulation: Research, theory, and applications (pp. 13-39). New York, NY: Guilford Press.

Carver, C. S., \& Scheier, M. F. (1981). Attention and self-regulation: A control-theory approach to human behavior. New York, NY: Springer-Verlag. http://dx.doi.org/10.1007/978-1-4612-5887-2

Carver, C. S., \& Scheier, M. F. (1990). Origins and functions of positive and negative affect: A control-process view. Psychological Review, 97, 19-35. http://dx.doi.org/10.1037/0033-295x.97.1.19

Carver, C. S., \& Scheier, M. F. (1998). On the self-regulation of behavior. New York, NY: Cambridge University Press. http://dx.doi.org/10.1017/cbo9781139174794

Carver, C. S., \& Scheier, M. F. (2009). Processus de contrôle, autorégulation et affect [Control processes and the self-regulation of action and affect]. In Y. Paquet (Ed.), Psychologie du contrôle: Théories et applications [The psychology of control: Theories and applications] (pp. 207-225). Brussels, Belgium: De Boeck.

Champion, L. A., \& Power, M. J. (1995). Social and cognitive approaches to depression: Towards a new synthesis. British Journal of Clinical Psychology, 34, 485-503. http://dx.doi.org/10.1111/j.2044-8260.1995.tb01484.x 
International Journal of Child, Youth and Family Studies (2015) 6(4.1): 709-729

Chong, I. G., \& Jun, C. H. (2005). Performance of some variable selection methods when multicollinearity is present. Chemometrics and Intelligent Laboratory Systems, 78, 103112. http://dx.doi.org/10.1016/j.chemolab.2004.12.011

Crocker, J., \& Park, L. E. (2004). The costly pursuit of self-esteem. Psychological Bulletin, 130, 392-414. http://dx.doi.org/10.1037/0033-2909.130.3.392

Désandes, E., \& Lacour, B. (2009). Les tumeurs solides [Solid tumors]. In D. Sommelet, J. Clavel, \& B. Lacour (Eds.), Epidémiologie des cancers de l'enfant [Epidemiology of childhood cancer] (pp. 55-66). Paris, France: Springer.

Dupuis, G., Perrault, J., Lambany, M. C., Kennedy, E., \& David, P. (1989). A new tool to assess quality of life: The Quality of Life Systemic Inventory. Quality of Life and Cardiovascular Care, 5, 36-45.

Dupuis, G., Taillefer, M. C., Rivard, M. J., Roberge, M. A., \& St-Jean, K. (2001). Quality of Life Systemic Inventory (QLSI): Sensitivity to change and psychometric characteristics. Annals of Behavioral Medicine, 23(Suppl. 160).

Eiser, C., Vance, Y. H., Horne, B., Glaser, A., \& Galvin, H. (2003). The value of the PedsQLTM in assessing quality of life in survivors of childhood cancer. Child: Care, Health and Development, 29(2), 95-102. http://dx.doi.org/10.1046/j.1365-2214.2003.00318.x

Elicker, J. D., Lord, R .G., Ash, S. R., Kohari, N. E., Hruska, B. J., McConnell, N. L., \& Medvedeff, M. E. (2010). Velocity as a predictor of performance satisfaction, mental focus, and goal revision. Applied Psycholoqy: An International Review, 59, 495-514. http://dx.doi.org/10.1111/j.1464-0597.2009.00409.x

Emmons, R. A. (1996). Striving and feeling: Personal goals and subjective well-being. In P. Gollwitzer \& J. Bargh (Eds.), The Psychology of Action: Linking cognition and motivation to behavior (pp. 312-337). New York, NY: The Guildford Press.

Etienne, A. M., Dupuis, G., Spitz, E., Lemétayer, F., \& Missotten, P. (2010). The gap concept as a quality of life measure: Validation study of the Quality of Life Systemic Inventory for Children. Social Indicator Research, 100, 241-257. http://dx.doi.org/10.1007/s11205-010-9614-7

Guyot-Goubin, A., \& Clavel, J. (2009). Les hémopathies malignes [Hematologic malignancy]. In D. Sommelet, J. Clavel, \& B. Lacour (Eds.), Epidémiologie des cancers de l'enfant [Epidemioloay of childhood cancer] (pp. 49-54). Paris, France: Springer. http://dx.doi.org/10.1007/978-2-287-78337-1_3

Higgins, E. T., Bond, R. N., Klein, R., \& Strauman, T. (1986). Self-discrepancies and emotional vulnerability: How magnitude, accessibility, and type of discrepancy influence affect. Journal of Personality and Social Psychology, 51, 5-15. http://dx.doi.org/10.1037//0022-3514.51.1.5

Klassen, A. F., Strohm, S. J., Maurice-Stam, H., \& Grootenhuis, M. A. (2010). Quality of life questionnaires for children with cancer and childhood cancer survivors: A review of the development of available measures. Supportive Care in Cancer, 18(9), 1207-17. http://dx.doi.org/10.1007/s00520-009-0751-y

Kovacs, M. (1985). The Children’s Depression Inventory (CDI). Psychopharmacology Bulletin, 21, 995-998.

Kovacs, M. (1992). The Children's Depression Inventory. North Tonawanda, NY: MultiHealth Systems.

Langeveld, N., Grootenhuis, M., Voute, P., \& de Haan, R. J. (2004). Posttraumatic stress 
symptoms in adult survivors of childhood cancer. Pediatric Blood \& Cancer, 42, 604-610. http://dx.doi.org/10.1002/pbc.20024

Lemétayer, F. (2007). L’enfant atteint d'un cancer: Répercussions sur sa vie scolaire [The child with cancer: Impacts on school life]. Revue Francophone du Stress et Trauma [Francophone Journal of Stress and Trauma], 7, 226-232.

Löf, C. M., Winiarski, J., Giesecke, A., Ljungman, P., \& Forinder, U. (2009). Health-related quality of life in adult survivors after paediatric allo-SCT. Bone Marrow Transplantation, 43, 461-468. http://dx.doi.org/10.1038/bmt.2008.338

McIntosh, W. D. (1996). When does goal nonattainment lead to negative emotional reactions, and when doesn't it? The role of linking and rumination. In L. L. Martin \& A. Tesser (Eds.), Striving and Feeling (pp. 53-79). Mahwah, NJ: Lawrence Erlbaum Associates. http://dx.doi.org/10.4324/9781315806396

Miller, G. A. Galanter, E., \& Pribam, K. H. (1960). Plans and the structure of behavior. New York, NY: Holt, Rinehart \& Winston. http://dx.doi.org/10.1037/10039-000

Missotten, P., Etienne, A. M., \& Dupuis, G. (2007). La qualité de vie infantile: Etat actuel des connaissances [The quality of infant life: Current knowledge]. Revue Francophone de Clinique Comportementale et Cognitive [Francophone Journal of Behavioural and Cognitive Clinical Medicine], 14, 16-27.

Moore, B. (2005). Neurocognitive outcomes in survivors of childhood cancer. Journal of Pediatric Psychology, 30, 51-63. http://dx.doi.org/10.1093/jpepsy/jsi016

Nathans, L. L., Oswald, F. L., \& Nimon, K. (2012). Interpreting multiple linear regression: A guidebook of variable importance. Practical Assessment, Research \& Evaluation, 17, 119.

Oberfield, S., \& Sklar, C. (2002). Endocrine sequelae in survivors of childhood cancer. Adolescent Medicine, 13, 51-63.

Pérez-Enciso, M., \& Tenenhaus, M. (2003). Prediction of clinical outcome with microarray data: A partial least squares discriminant analysis (PLS-DA) approach. Human Genetics, 112, 581-592.

Scheier, M. F., \& Carver, C. S. (2003). Goals and confidence as self-regulatory elements underlying health and illness behaviour. In L. D. Cameron \& H. Leventhal (Eds.), The Selfrequlation of health and illness behaviour (pp. 17-41). London, UK: Routledge. http://dx.doi.org/10.4324/9780203553220

Sommelet, D. (2009). Notion de guérison: Séquelles et complications tardives, suivi à long terme [Healing concept: Long-term monitoring of sequelae and late complications]. In D. Sommelet, J. Clavel, \& B. Lacour (Eds.), Epidémiologie des cancers de l'enfant [Epidemiology of childhood cancer] (pp. 55-66). Paris, France: Springer. http://dx.doi.org/10.1007/978-2-287-78337-1_10

Spielberger, C. D., Edwards, C. D., Lushene, R. E., Montuori, J., \& Platzek, D. (1973). Preliminary manual for the State-Trait Anxiety Inventory for Children. Palo Alto, CA: Consulting Psychologists Press.

Street, H. (2002). Exploring relationships between goal setting, goal pursuit and depression: A review. Australian Psychologist, 37, 95-103. http://dx.doi.org/10.1080/00050060210001706736

Street, H., Nathan, P., Durkin, K., Morling, J., Azahar Dzahari, M, Carson, J., \& Durkin, E. (2004). Understanding the relationships between wellbeing, goal-setting and depression in 
children. Australian and New Zealand Journal of Psychiatry, 38, 155-161. http://dx.doi.org/10.1080/j.1440-1614.2004.01317.x

Tenenhaus, M. (1998). La régression PLS: Théorie et pratique [PLS regression: Theory and practice]. Paris, France: Technip.

Turgeon, L., \& Chartrand, E. (2003). Psychometric properties of the French-Canadian version of the State-Trait Anxiety Inventory for Children. Educational and Psychological Measurement, 63, 174-185.

Varni, J. W., Burwinkle, T. M., Katz, E. R., Meeske, K., \& Dickinson, P. (2002). The PedsQLTM in pediatric cancer: Reliability and validity of the Pediatric Quality of Life Inventory generic core scales, multidimensional fatigue scale, and cancer module. Cancer, 94, 2090-2105. http://dx.doi.org/10.1002/cncr.10428

Wold, S., Sjöström, M., \& Eriksson, L. (2001). PLS-regression: A basic tool of chemometrics. Chemometrics and Intelliqent Laboratory Systems, 58, 109-130. http://dx.doi.org/10.1016/s0169-7439(01)00155-1

Wrosch, C., Miller, G. E., Scheier, M. F., \& Brun de Pontet, S. (2007). Giving up on unattainable goals: Benefits for health? Personality and Social Psychology Bulletin, 33, 251-265. http://dx.doi.org/10.1177/0146167206294905

Wrosch, C., Scheier, M. F., Carver, C. S., \& Schulz, R. (2003a). The importance of goal disengagement in adaptive self-regulation: When giving up is beneficial. Self and Identity, 2, 1-20. http://dx.doi.org/10.1080/15298860309021

Wrosch, C., Scheier, M. F., Miller, G. E., Schulz, R., \& Carver, C.S. (2003b). Adaptive selfregulation of unattainable goals: Goal disengagement, goal reengagement, and subjective well-being. Personality and Social Psychology Bulletin, 29, 1495-1508. http://dx.doi.org/10.1177/0146167203256921

Zebrack, B. J., Yi, J., Petersen, L., \& Ganz, P. A. (2008). The impact of cancer and quality of life for long-term survivors. Psycho-Oncology, 17, 891-900. http://dx.doi.org/10.1002/pon.1300 